\title{
The impact of the transition of hot water "preparation" by means of individual heating stations on the Kazan energy system
}

\author{
I $N$ Zapolskaya ${ }^{1, *}, Y u V$ Vankov $^{2}, O I Z_{\text {Zverev }}^{3}$ and $R R$ Rotach $^{4}$ \\ ${ }^{1}$ JSC Tatenergo branch, the Kazan thermal networks, Kazan, Russia \\ ${ }^{2}$ Kazan State Power Engineering University, Kazan, Russia \\ ${ }^{3}$ JSC Tatenergo, Kazan, Russia \\ ${ }^{4}$ LLC KER-AVTOMATIKA
}

\begin{abstract}
The result of the implementation of technical solutions should be evaluated in terms of the effect on the power system as a whole. At the same time, the main task is to obtain a socio-economic effect noticeable for the consumer of energy resources, as he is a key figure of the energy system. The article considers the influence of modernization of hot water supply systems (HWS) by transferring the function of hot water preparation in apartment buildings to individual heating stations (IHS) from the district heating stations (DHS) with their subsequent liquidation, as well as the elimination of hot water supply grid. The expected result of these measures is the reduction in heat energy loss in heat carrier agents in heating networks, as well as improving the quality and reliability of the hot water supply system and the possible reduction of energy consumption by residents in apartment buildings. The effect on the operation of the heat supply system will not be provided by IHSs themselves, but by automatic controllers, installed together with them. This, in turn, will make it possible for the Central Heating and Power plants (boiler) to be modernized in operation in a timely manner, to improve the system's efficiency. Computational studies were carried out in order to assess the impact of the transition from IHS to hot water supply on the energy system.
\end{abstract}

\section{Introduction}

Much attention is currently paid to the problems of improving the efficiency of heating systems, as it is one of the most socially significant sectors of economy. For urban heating systems, these issues become more acute, as they are the most complex and expensive in the housing sector. In the bills of apartment houses residents, the share of payment for thermal resources exceeds $40 \%$.

One of the ways to increase the efficiency of heat supply is to reduce heat losses by decommissioning district heating stations and hot water supply grids with transferring the function of "preparing" hot water to the consumer by installing an IHS with individual waterwater heaters (IWWH) [1-3].

The research, carried out in the cities of Naberezhnye Chelny and Kazan, showed that the above mentioned actions not only will have a positive impact on the efficiency of heat supply grids, but also will improve the quality and reliability of hot water supply for consumers [4].

In this case, the most important part in making technical decisions is to evaluate the effect on the energy system as a whole. The positive effect is considered to be obtained only if there is a noticeable improvement in technical, financial and economic performance indicators of both heat supply grids and heat supply sources (combined heat and power (CHP) plants, boiler houses).
Moreover, these measures eventually will bring the socio-economic effect to an energy resource consumer.

The operation mode of a heating unit of a CHP plant and a territorial boiler house (i.e. pressure in the supply and return pipelines and temperature in the supply pipelines) must be set in accordance with the goals of a heat supply grid manager. Deviations from the specified mode for the head valves of a CHP plant (the boiler house) should be no more than:

- as for the temperature of water entering the heating network, $+/-3 \%$;

- as for the pressure in the supply pipelines $+/-5 \%$;

- as for the pressure in return pipelines $+/-0.2 \mathrm{~kg}(\mathrm{f}) /$ $\mathrm{cm} 2(+/-20 \mathrm{kPa})[5]$

Besides, it is necessary to take into account that the pricing for electrical energy supplied by the stations is formed in accordance with the rules of operation in the wholesale market of energy and electric power [6].

\section{The impact of the modernization of the hot water supply system by installing individual heating stations in the energy system of Kazan}

Kazan JSC Tatenergo implemented the program of transition to IHS in its heat supply grids, which stipulated the installation of 1,353 IHS modules in

Corresponding author: zapolskayain@ tatenergo.ru 


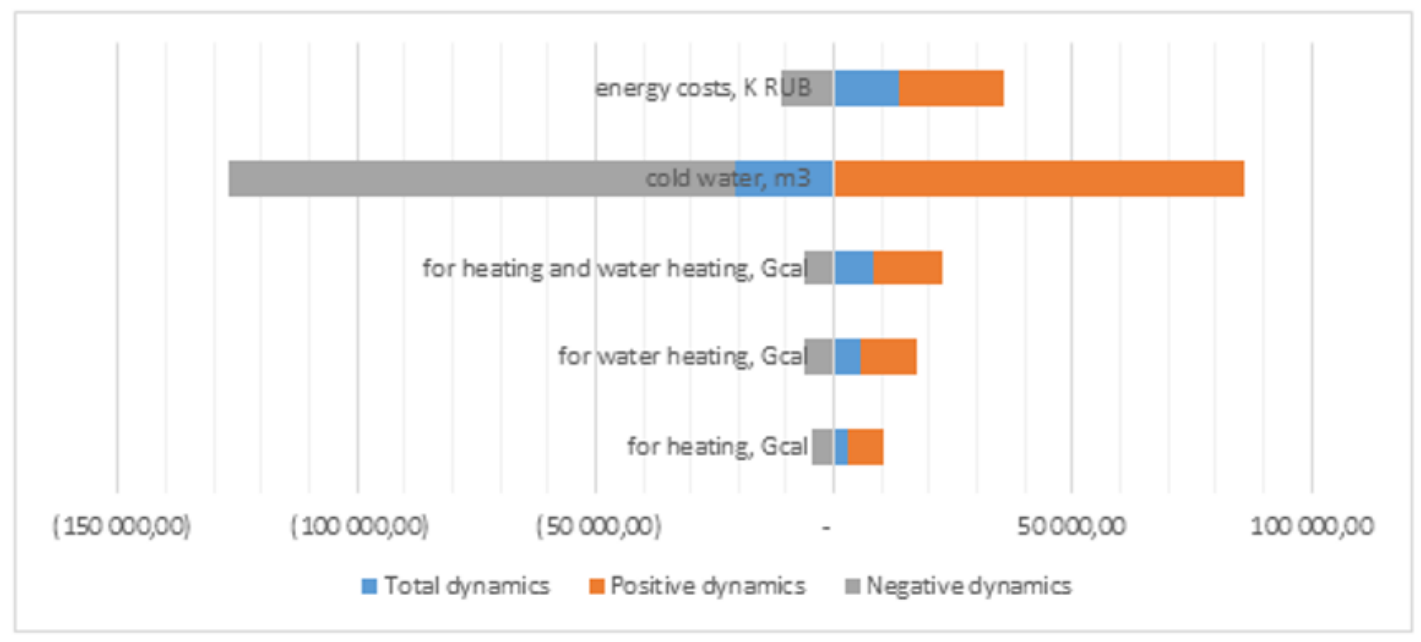

Fig. 1. Changes in energy consumption in 131 apartment houses in 2016 and 2018.

apartment buildings, during 2017-2018; at the same time 105 district heating stations and 244 linear kilometers of the heating networks of hot water supply were liquidated.

In 2018, as a result of the implemented program, it was possible to reduce the amount of heat energy loss by 41.3 thousand Gcal. compared to 2017 (or by $4.2 \%$ ) and the loss of a heat carrier by 307.7 thousand tons (or by $17.8 \%$ ).

The comparison of heat consumption before and after the installation of IHSs in apartment buildings participating in this program also showed the effect of the modernization of the HWS.

The analysis was carried out on different types of apartment buildings connected to the distict heating stations in different energy districts of the city of Kazan. The sample involved 131 premises.

The study included the analyses of the consumption of heat energy for heating and hot water supply as well as the consumption of cold water for the needs of hot water supply in accordance with the two-component tariff for hot water established in the Republic of Tatarstan.

Years 2016 and 2018 (before and after the installation of IHSs) were chosen for reference.

Calculations were made in accordance with Section 2, Article 19 of the Federal Law dated July 27, 2010 No. 190-FZ; Article 13 of the Federal Law dated November 23, 2009 No. 261 "On Energy Saving and Energy Efficiency Improvement and on Amendments to Certain Legislative Acts Of the Russian Federation "; in accordance with Section 5, Resolution No. 1034 "On Commercial Measurement for Heat Energy, Heat Carrier"; sections 1 and 2 of Article 157 of the Housing Code of the Russian Federation; Article 544 of the Civil Code of the Russian Federation.

Figure 1 shows the results of the analysis of the energy consumption in apartment houses before and after the installation of the IHS. In monetary terms, 100 houses out of 131 got the positive effect, with the annual amount of savings being more than 20 million rubles, while 31 house got an additional financial burden of 11 million rubles. In 2018, the total economic effect on the aggregate sampling in apartment houses was more than 13 million rubles.

Taking into account the dependence of the consumption of the heat energy for heating on the outside temperature, when comparing the consumption of the heat energy for heating in 2016 with that in 2018, we have been comparing the ratio of consumption during a specific year to the average temperature during that year. Thus, the leveling effect of the outdoor temperature on the annual heat consumption of the selected houses for heating was accounted for.

We have stated that the main economic effect is achieved by reducing the consumption of thermal energy, which in the aggregate sampling of houses was about $4.9 \%$. This fact is confirmed by the general decrease by $5.59 \%$ in the net heat supply of JSC Tatenergo to the "Residents" group in the city of Kazan.

Figure 2 presents the data on the useful heat supply to consumers who have switched to IHS for the "preparation" of hot water in apartment houses of Kazan, in the periods before and after the transition (2016 and 2018). For the analysis, the net output in 2016 was adjusted for the average annual temperature in 2018.

To eliminate the influence of the value of the introduced heated areas in 2018, compared to 2016, a relative indicator was calculated, reflecting the amount of heat energy (Gcal) per $1 \mathrm{~m} 2$ of heated area. The change in this ratio also showed a decrease in heat consumption by $12.6 \%$. (from $0.22 \mathrm{Gcal} / \mathrm{m} 2$ to 0.19 $\mathrm{Gcal} / \mathrm{m} 2$ ). The reason for the decrease in produced supply is the installation of IHS in the apartment houses together with the nodes of weather control (NWC).

\section{The impact of the modernization of the hot water system by installing individual heating stations on the heat supply sources in the city of Kazan}

The main sources of thermal energy in Kazan are three CHP plants, i.e. two belonging to JSC Tatenergo: Kazan 


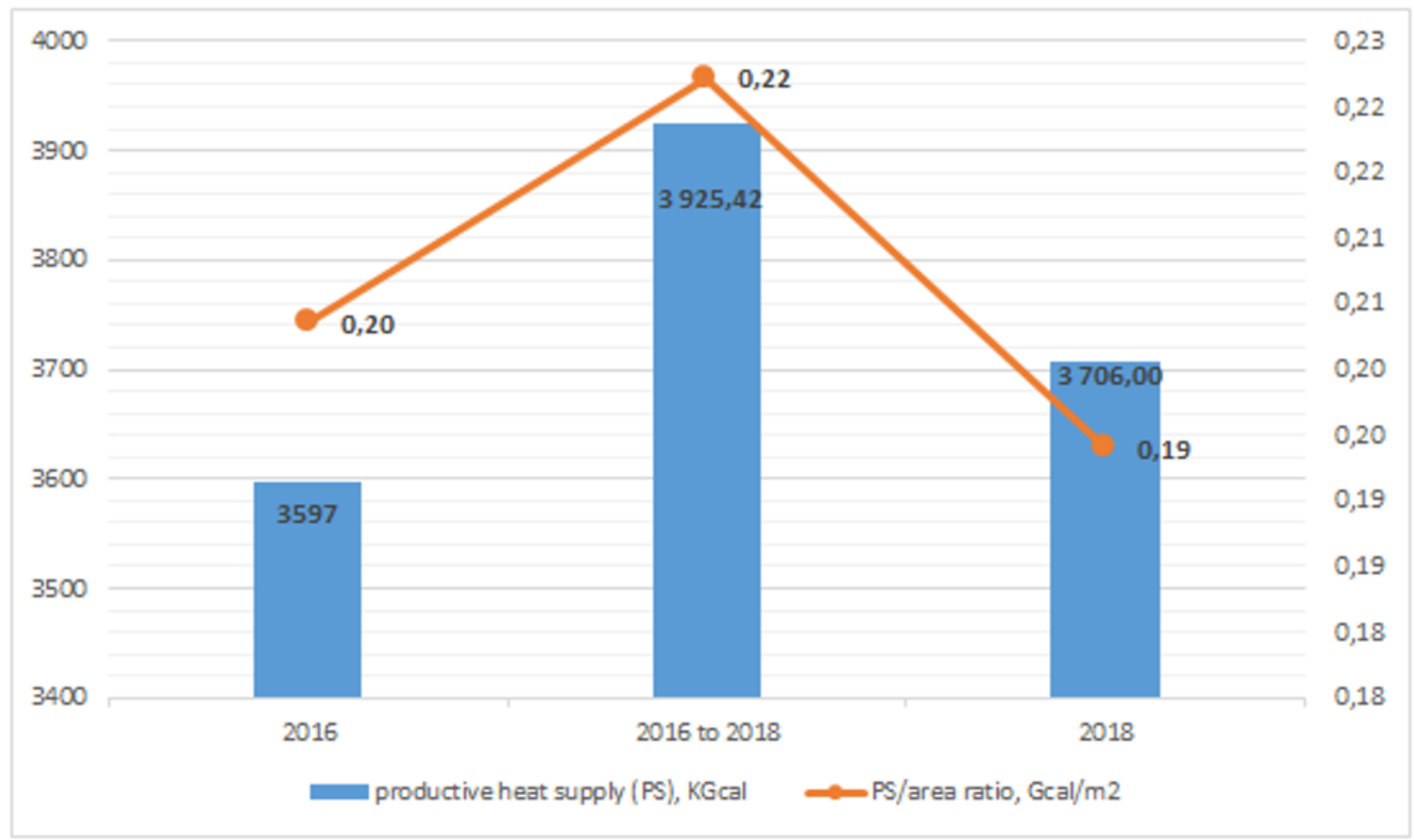

Fig. 2. The shift in heat supply in the "Residents" group in Kazan $(2016,2018)$.

CHP 1 and 2, and JSC TGC-16, and three district boiler houses (belonging to JSC Tatenergo).

Mainly the profitability of CHP plant operation depends on the amount of heating output. The higher is the heating output, the better is the utilized capacity of the samplings, the lower are heat losses at the CHP plants, and the higher is the efficiency of the plant. The effect is achieved by reducing losses in the condensation of steam at the outlet of the turbine. The analysis carried out by the authors [7] showed that when $35 \%$ of the thermal power of steam is used by consumers, the reduction in condensation losses turns out to be $28 \%$. This means that the increase in the supply of heat to consumers by $1 \%$ gives an increase in the efficiency of thermal power plants by $0.8 \%$. Thus, a decrease in heat supply from a CHP plant is an unfavorable factor for its efficiency.

The reducing of the supply of heat energy by installing automated individual heating stations with weather control units by $5.59 \%$ can result in a decrease in the efficiency of CHPP operation by $4.47 \%$.

On the other hand, the reduction in the net heat supply to consumers is the result of measures taken in the framework of the implementation of the Federal law No. 261 dated 11.23.2009 "On energy saving and on increasing energy efficiency, and on introducing changes to certain legislative acts of the Russian Federation".

In the actualized scheme of heat supply in Kazan with a view up to year 2033, a decrease in the supply of heat energy has also been stated [8]. The following factors to explain the reasons for the decline are given in the document:
1) the increase in the efficiency of existing regulatory systems (introduction of new automated and modernization of existing consumer IHSs).

2) the liquidation and renovation of run-down residential housing.

3 ) the elimination or reduction of the ventilation load of consumers.

4) the advancement in the energy efficiency of conserved funds (installation of energy-efficient windows, insulation of building facades, elimination of overheating through the introduction of modern highperformance equipment, etc.).

5 ) the reduction of actual losses in heat supply grids due to their reconstruction.

6) the actual climatic characteristics of the heating period and its duration.

The negative impact of these factors on the efficiency of a CHP plant is compensated by the increase in the consumption of heat energy in newly constructed premises. According to the heat supply scheme, the city of Kazan for the period up to 2033 is expected to increase the connected load in the centralized heat supply zone by 3.6 times (up to $560 \mathrm{Gcal} / \mathrm{hr}$ ) as compared to 2018. The indicator is predicted by taking into account the population growth by $11 \%$ and an increase in the area of multi-storey apartment building stock by $19.9 \%$.

After JSC Tatenergo (CHP plants, boiler houses) heat supply sources had transferred the function of "preparing" hot water from central heating stations to individual heating stations, significant fluctuations in network water consumption were observed during the day. In Kazan, fluctuations of up to $2,900 \mathrm{t} / \mathrm{hr}$ were recorded. A similar situation was observed after 
Table 1. Daily fluctuations in the flow rate of network water during the transition to Electronic Individual Heating Plants.

\begin{tabular}{|c|c|c|c|}
\hline & IHS \% & \multicolumn{2}{|c|}{ Maximum flow rate during the day } \\
\hline & & $\mathbf{t} / \mathbf{h r}$ & \% \\
\hline Kazan & $\begin{array}{c}24 \text { (Stage 1 of the 2016 } \\
\text { program) }\end{array}$ & 2900 & 9 \\
\hline Naberezhnye Chelny & More than 90 & 4000 & 26.7 \\
\hline
\end{tabular}

switching multi-storey apartment buildings to the Electronic Individual Heating Plants (EIHP) in Naberezhnye Chelny (Table 1).

The deviation of parameters from the dispatching schedule of heat load by more than $9 \%$ in a short period of time, most notably, the change in pressure of the network water through the supply and return pipelines in the main heat pipe, violates the requirements for stationary heat and power plants in accordance with paragraph 4.11.1 of the Regulations for pipeline technical maintenance of electric power stations and networks of the Russian Federation, approved by the Act N 229 of the Ministry of Energy of Russia dated June 19, 2003. As indicated in this paragraph, pressure deviations from the specified mode of main valves of the power plant (boiler houses) in the supply pipelines should not exceed $5 \%$.

Intense fluctuations in heat consumption are typical for the heating period with sharp drops in outside air temperature, which leads to a transition from the qualitative regulation of the mode of heat supply to the quantitative one.

The increase in the level of daily irregularity is also noted after heat consumers are connected to the heat network through the Electronic IHS with weather control nodes. The operation of automated IHSs significantly affects the hydraulic regime of the urban heat supply system. The rates of delivery water vary significantly depending on the time of the day and on the outdoor temperature [7].

The daily variations of consumption of delivery water in the heating network have a negative effect on both the work of the CHP plants and the boiler houses. The expansion of the ranges of daily fluctuations in pressure and flow of the delivery water leads to emergency situations in the heating system. It brings forth damages within the district heating stations that leads to an increase in boiler make-up water and interruption of heat carrier to residential houses.

Fluctuations are also possible with a sharp change in the outside air temperature during the heating period. Consequently, the heat supply sources should be ready for such changes regardless of the kinds of Weather Control Nodes installed in apartment houses.

The effective regulation of the parameters of the heating network in an extended range of daily fluctuations of the parameters of the heating network can be made possible by equipping heat supply sources with frequency-regulated systems for the performance of network pumps, namely, by retrofitting pumps with a variable frequency drive (VFD).
These activities, carried out at the heat supply sources of JSC Tatenergo, not only neutralize the influence of sharp daily fluctuations of the flow rate of the delivered water on the hydraulic mode of the heat supply system, but also increase the economic effect obtained by reducing the power consumed by the network pumps, and electric power consumption by $7 \%$ according to the conducted computation.

The deviation of the actual parameters from a given schedule of heat and electric loads also influences the efficiency of the CHP plant operation in the conditions of operation in the wholesale electricity and capacity market (WECM).

In order to optimize CHP plant operation modes, as a result of the formation of a competitive price on the wholesale market, work is planned on the WECM taking into account the specified forecast parameters of the heat carrier temperature, consumption mode and heat network consumption for prior periods and similar periods of previous years [6].

Provided the compliance of the initial indicators adopted for the calculation of the actual indicators for the planning period, the selected operating mode of the station makes it possible to follow the specified thermal and electrical power schedules without sacrificing reliability and cost effectiveness for the process of production.

Consequently, the sharp fluctuations of the specified parameters, including the flow rate of network water, will certainly affect the specified modes of operation of CHP plant on the WECM. In most cases, this leads to a shortage of thermal power at the output of turbines operating according to a planned dispatching time program of electric energy demands.

If it is not possible to compensate for the heat by heating output, it is necessary to coordinate the planned dispatching schedule of the plant's electrical capacity with the system operator (if the deviation is more than $2 \%$ of to the required values), which affects the pricing of electricity in the wholesale market, and, as a result, the station's performance as well.

Such situations arise (primarily during the period of stabilizing the pressure in the heat supply grid), when it is necessary to use the turbines in a disadvantageous condensation mode to maintain the dispatching schedule of electric energy demands. Moreover, taking into account the varying schedule of consumption of heat power by consumers, regardless of the reasons, CHP plants should be ready for these changes in order to increase their efficiency. The leveling of thermal power fluctuations at the CHP plant must be carried out by 
taking into account the economic and technical features of the operation of the plant. It can be in the form of the addition of a peak water boiler (PVB), the installation of pressure reducing-cooling devices equipment (PRC), and the use of hot water storage tanks.

\section{Conclusion}

Modern realities place strict requirements for the operation of power systems, which should ensure not only reliable and uninterrupted power supply to consumers, but also increase their cost-effectiveness in order to reduce the cost of supplied energy resources.

At the same time, it is necessary to consider any measures aimed at improving the efficiency of energy facilities in terms of their impact on the energy complex as a whole - from the consumer to the energy supply source.

The modernization of heat supply systems by transferring the water "preparing" to the consumer by the installation of individual heating stations with individual water heaters and weather control nodes has shown its effectiveness.

As a result of the measures taken, the following effect was obtained:

1. fie the consumers of thermal energy:

- an improvement of the quality of hot water supply and a reduction in periods of hot water supply shutting down;

- a reduction of the consumption of heat energy in the DHW (on average up to $20 \%$ );

2. for the heat supply grids:

- a reduction in the loss of heat energy and heat carrier in the hot water supply grid;

- a reduction of the cost of maintaining the district heating station and the DHW network included in the tariff for thermal energy.

Notwithstanding the consequences, marked of the operation of heat supply sources, steaming from the installation of IHSs with weather control nodes, by disrupting the hydraulic mode of the networks, deviating the parameters of the network water consumption from the planned schedule of electrical energy supply and by reducing the net heat output, it still made it possible for the CHP plants to take into account these factors and timely adjust to the new operation conditions, taking into account present-day challenges prioritizing, first of all, consumers' requirements.

\section{References}

1. I.N. Zapolskaya, Yu.V. Vankov, Sh.G. Ziganshin, A.F. Valeev, O.I. Zverev, Reduction of heat losses of the energy supplying organization by modernization of hot water supply systems, Bulletin Kazan State Power Engineering University, B4(36), 54-64 (2017)

2. Yu.V. Vankov, I.N. Zapolskaya, E.V. Izmaylova, A.R. Zagretdino, R.N. Valiev, Reduction of heat losses of the energy supplying organization by modernization of hot water supply systems,
Bulletin Kazan State Power Engineering University, B4, 13-24 (2018)

3. Yu.V. Vankov, I.N. Zapolskaya, E.V. Izmaylova, A.R. Zagretdinoand, L.V. Plotnikova, Reduction of energy consumption in the transition to hot water from individual heating points, Bulletin Kazan State Power Engineering University, B1, 19-27 (2019)

4. V.I. Sharapov, E.U. Yamleev, The techniques of protecting net and make-up water from aeration, $176(2012)$

5. The Order of the Ministry of Energy of Russia dated June 19, 2003 No. 229 (as amended on February 11, 201) "On Approval of the Rules for Technical Operation of Power Stations and Networks of the Russian Federation.

6. The Resolution of the Government of the Russian Federation dated August 31, 2006. № 529 "On improving the functioning of the wholesale market of electric energy (power)".

7. M.A. Aksenov, Heating network, 352 (1965)

8. The scheme of heat supply of the municipal entity of the city of Kazan up to year 2033. "Kazan State Power Engineering University", 152 (2017)

9. B.V. Yakovlev, Improving the efficiency of district heating introduction and heating supply systems, 448 (2008)

10. Yu.N. Zvonareva, Yu.V. Vankov, The functioning of a heat supply system during the phased introduction of automated individual heat centers, News of universities. PROBLEMS OF ENERGY, B19(1-2), 164-69 (2017)

11. V.G. Semenov, V.G. Baron, Talk of A.S. Individual heating stations of the new generation, Energy Saving, B7, 30-37 (2017)

12. V.K. Zhukov, Economic efficiency of the mass introduction of individual thermal centers in the city of Elabuga, Energy Council, B5(36), 36-37 (2014)

13. V.N. Orekhov, Indicators of quality of heat supply, News of heat supply, B5(141) (2012)

14. Yu.N. Zvonareva, Commercial Energy Management Control Publication of the results of the Scientific and Technical, International Conference "PromEngineering 2017" SHS Web of Conferences, 35, 01124 (2017) DOI: 10.1051 / shsconf / 20173501124

15. A. Teekaram, A. Palmer, Variable-flow water systems. Design. Installation and commissioning guidance, 81 (2002) 